LA W RENCE LIVERMORE NATIONAL LABORATORY
Chemical Kinetic Modeling of Combustion of Automotive Fuels

W. J. Pitz, C. K. Westbrook, E. J. Silke

November 15, 2006 
This document was prepared as an account of work sponsored by an agency of the United States Government. Neither the United States Government nor the University of California nor any of their employees, makes any warranty, express or implied, or assumes any legal liability or responsibility for the accuracy, completeness, or usefulness of any information, apparatus, product, or process disclosed, or represents that its use would not infringe privately owned rights. Reference herein to any specific commercial product, process, or service by trade name, trademark, manufacturer, or otherwise, does not necessarily constitute or imply its endorsement, recommendation, or favoring by the United States Government or the University of California. The views and opinions of authors expressed herein do not necessarily state or reflect those of the United States Government or the University of California, and shall not be used for advertising or product endorsement purposes.

This work was performed under the auspices of the U.S. Department of Energy by University of California, Lawrence Livermore National Laboratory under Contract W-7405-Eng-48. 


\title{
Chemical Kinetic Modeling of Combustion of Automotive Fuels
}

\author{
William J. Pitz (Primary Contact), Charles K. Westbrook, Emma J. Silke \\ Lawrence Livermore National Laboratory \\ P. O. Box 808 , L-372 \\ Livermore, CA 94551 \\ Phone: (925-422-7730) ; Fax: (925-424-4334) \\ E-mail: pitz1@1lnl.gov
}

DOE Technology Development Managers: Gurpreet Singh and Kevin Stork Phone: (202-586-8306)

E-mail: kevin.stork@ee.doe.gov

\section{Objectives}

- Develop detailed chemical kinetic reaction models for components of fuels, including olefins and cycloalkanes used in diesel, spark-ignition and HCCI engines

- Develop surrogate mixtures of hydrocarbon components to represent real fuels and lead to efficient reduced combustion models

- Characterize the role of fuel composition on production of emissions from practical automotive engines

\section{Accomplishments}

- Completed models for chemical kinetics of combustion of three major fuel components, methyl cyclohexane and di-isobutylene and assembled model for cyclohexane.

- Continued development of surrogate mixtures to describe HCCI ignition

\section{Future Directions}

- Extend model capabilities to additional classes of fuel components, including biodiesel components and larger hydrocarbon components.

- Validate model for chemical kinetics of combustion for cyclohexane. Use new reaction rate rules for cyclohexane to improve methyl cyclohexane model.

- Continue development of increasingly complex surrogate fuel mixtures

- Investigate the effect of fuel molecular structure on sooting under diesel engine conditions.

- Increase collaborations with programs outside LLNL dealing with automotive fuel issues

\section{$\underline{\text { Introduction }}$}


Automotive hydrocarbon fuels consist of complex mixtures of hundreds or even thousands of different components. These components can be grouped into a number of structurally distinct classes, consisting of n-paraffins, branched paraffins, cyclic and branched cyclic paraffins, olefins, oxygenates, and aromatics. The fractional amounts of these mixtures are quite different in gasoline, diesel fuel and oil-sand derived fuels, which contributes to the very different combustion characteristics of each of these types of combustion systems.

To support large-scale computer simulations of each kind of engine, it is necessary to provide reliable chemical kinetic models for each of these fuel classes. However, few specific hydrocarbon components of some of these fuel classes have been modeled. For example, models for benzene and toluene have been developed, although models for few if any larger aromatic compounds such as naphthalene or styrene currently exist. Similarly, detailed models for small nparaffins such as propane, $n$-heptane and even n-octane have been developed, but detailed models do not yet exist for the much larger versions such as n-hexadecane, characteristic of diesel fuels. Current approaches to this problem are to construct a detailed model, containing one or more representatives of each class of components to serve as a surrogate mixture. In order for such a surrogate mixture model to be useful, each component must have a well-tested detailed kinetic model that can be included. This high-level approach can create realistic substitutes for gasoline or diesel fuel that reproduce experimental behavior of the practical real fuels, but these substitutes, or surrogates, will also then be reproducible in both experiments and modeling studies. Detailed kinetic models for groups of fuels can then be simplified as needed for inclusion in multidimensional CFD models or used in full detail for purely kinetic modeling.

\section{Approach}

Chemical kinetic modeling has been developed uniquely at LLNL to investigate combustion of hydrocarbon fuels in practical combustion systems such as diesel and HCCI engines. The basic approach is to integrate chemical rate equations for chemical systems of interest, within boundary conditions related to the specific system of importance. This approach has been used extensively for diesel and HCCI engine combustion, providing better understanding of ignition, soot production, and NOx emissions from these engines in fundamental chemical terms.

The underlying concept for diesel engines is that ignition takes place at very fuel-rich conditions, producing a mixture of chemical species concentrations that are high in those species such as acetylene, ethene, propene and others which are well known to lead to soot production. Some changes in combustion conditions reduce the post-ignition levels of these soot precursors and reduce soot production, while other changes lead to increased soot emissions. The LLNL program computes this rich ignition using kinetic modeling, leading to predictions of the effect such changes might have on soot production and emissions.

Ignition under HCCI engine conditions is closely related to that in diesel engines, since both are initiated by compression ignition of the fuel/air mixtures. In very fuel-lean HCCI ignition, the premixing of fuel and air in the gaseous state results in no soot and extremely low NOx production. Kinetic modeling has proven to be exceedingly valuable in predicting not only the time of ignition in HCCI engines, but also the duration of burn and the emissions of unburned hydrocarbons, $\mathrm{CO}$, NOx and soot.

\section{$\underline{\text { Results }}$}

During the last, year we completed chemical mechanisms for important components to include in surrogate models for gasoline, diesel and oil-sand derived fuels. These components are 
diisobutylene and methylcyclohexane. First, a diisobutylene mechanism was developed to represent olefins in gasoline. In our work on diisobutylene, we discovered key reaction routes that affect the oxidation of large olefins. These routes involve the consumption of resonantly stabilized radicals that are produced by large olefins. These reaction routes accelerate the ignition of diisobutylene and are an important inclusion in the mechanism to enable proper prediction ignition delay times under engine conditions. In collaboration with Magnus Sjöberg and John Dec at Sandia, we used our newly developed mechanism for diisobutylene to model the HCCI engine experiments. We found the diisobutylene model simulated well the ignition phasing in the HCCI engine as a function of equivalence ratio (Fig. 1). We published our work on the development of a diisobutylene mechanism in the Proceedings of the Combustion Institute.

Mechanisms for methylcyclohexane and cyclohexane were developed to represent cycloalkanes in gasoline, diesel and oil-sand derived fuels. For methylcyclohexane $(\mathrm{MCH})$, we completed a paper documenting our development of a mechanism for $\mathrm{MCH}$ and our mechanism validation by comparisons to experiments in a rapid compression machine (Fig. 2). In the $\mathrm{MCH}$ work, we were able to establish new reaction rate rules that will assist us in developing further mechanisms for higher molecular weight cycloalkanes. These rules relate particularly to rate constants for reactions responsible for low temperature heat release. It is critical to get these rate constants correct for modeling of combustion in HCCI engines. We collaborated Magnus Sjöberg and John Dec at Sandia and used our MCH mechanism to model their experiments in an HCCI engine (Fig. 3). We used our new MCH mechanism to simulate the ignition phasing of $\mathrm{MCH}$ in an $\mathrm{HCCI}$ engine as a function of equivalence ratio (Fig. 3). The agreement between the predictions and the experiment are quite good. The paper on $\mathrm{MCH}$ mechanism development and validation will be published in the Proceedings of the Combustion Institute.

This year, we began assembling and testing a mechanism for cyclohexane to use to represent cycloalkanes in gasoline, diesel and oil-sand derived fuels. The mechanism testing will be completed in FY07. We compared results from our detailed chemical kinetic model to experimental results in a rapid compression machine in the literature (Fig. 4). We found that we could simulate both the ignition delay under engine-like conditions and we could also simulate the combustion products produced (Fig. 5). This work will be written up for a journal publication in FY07. Refinements in reaction rate rules determined in this work will be applied later to cycloalkanes of higher molecular weight needed in surrogate mechanisms for diesel and oil-sand derived fuels.

During this year, we wrote a landmark paper on the effect of oxygenates on sooting tendencies under diesel engine conditions. This paper represented a culmination of our DOE supported work on oxygenated fuels over the last 10 years. We used our kinetic model to show how different oxygenates, ester structures in particular, can have different soot-suppression efficiencies due to differences in the molecular structure of the oxygenated species.

\section{Conclusions}

Kinetic modeling provides a unique tool to analyze combustion properties of diesel, sparkignition and HCCI engines. A kinetic model can be very cost-effective as an alternative to extended experimental analyses and as guidance for more efficient experimentation, and computations can also provide a fundamental explanation of the reasons for the observed results. LLNL kinetic models are providing this valuable capability for engine research at many university and industrial facilities in the United States and are an essential tool in engine research. 


\section{FY 2006 Publications/Presentations}

1. W. J. Pitz, C. V. Naik, T. Ní Mhaoldúin, C. K. Westbrook, H. J. Curran, J. P. Orme, and J. M. Simmie, "Modeling and Experimental Investigation of Methylcyclohexane Ignition in a Rapid Compression Machine", Proceedings of the Combustion Institute, Volume 31, In press, 2007.

2. Metcalfe, W. K., Pitz, W. J., Curran, H. J., Simmie, J. M., and Westbrook, C. K. "The Development of a Detailed Chemical Kinetic Mechanism for Diisobutylene and Comparison to Shock Tube Ignition Times", Proceedings of the Combustion Institute, Volume 31, In press, 2007.

3. Naik, C.V., Pitz, W.J., Sjöberg, M., Dec, J.E., Orme, J., Curran, H. J., Simmie, J. M., and Westbrook, C.K., "Detailed Chemical Kinetic Modeling of Surrogate Fuels for Gasoline and Application to an HCCI Engine", SAE 2005 Transactions of Fuels and Lubricants, Presented at the 2005 Fall Powertrain and Fluid Systems Conference \& Exhibition, San Antonio, Texas. SAE paper 2005-01-3742, 2005.

4. Westbrook, C. K., Pitz, W.J., and Curran, H. J., "A Chemical Kinetic Modeling Study of the Effects of Oxygenated Hydrocarbons on Soot Emissions from Diesel Engines." Journal of Physical Chemistry A, 110, 6912-6922, 2006.

5. J. P. Orme, H. J. Curran, J. M. Simmie, "An Experimental and Modelling Study of Methyl Cyclohexane Pyrolysis and Oxidation", J. Phys. Chem. A, 110:114-131 (2006).

6. Pitz, W. J., Cernansky, N. P., Dryer, F. L., Egolfopoulos, F. N., Farrell, J. T., Friend, D. G., and Pitsch, H., "Development of an Experimental Database and Chemical Kinetic Models for Surrogate Gasoline Fuels", submitted, 2007 SAE World Congress, Detroit, MI.

7. Saylam, A., Ribaucour, M., Pitz, W. J., and Minetti, R., "Reduction of Large Detailed Chemical Kinetic Mechanisms for Autoignition Using Joint Analyses of Reaction Rates and Sensitivities”, International Journal of Chemical Kinetics, submitted, 2006.

Presentations:

1. W. J. Pitz, C. V. Naik, T. Ní Mhaoldúin, C. K. Westbrook, H. J. Curran, J. P. Orme, and J. M. Simmie, "Modeling and Experimental Investigation of Methylcyclohexane Ignition in a Rapid Compression Machine", $31^{\text {st }}$ International Symposium on Combustion, Heidelberg, Germany, August 8, 2006.

2. Metcalfe, W. K., Pitz, W. J., Curran, H. J., Simmie, J. M., and Westbrook, C. K. “The Development of a Detailed Chemical Kinetic Mechanism for Diisobutylene and Comparison to Shock Tube Ignition Times", $31^{\text {st }}$ International Symposium on Combustion, Heidelberg, Germany, August 8, 2006.

3. Naik, C.V., Pitz, W.J., Sjöberg, M., Dec, J.E., Orme, J., Curran, H. J., Simmie, J. M., and Westbrook, C.K., "Detailed Chemical Kinetic Modeling of Surrogate Fuels for Gasoline and Application to an HCCI Engine", 2005 Fall Powertrain and Fluid Systems Conference \& Exhibition, San Antonio, Texas. (SAE Oral Presentation Award).

4. C. K. Westbrook and W. J. Pitz, "Estimation Strategies for Chemical Kinetic Reaction Rates", 11th International Conference on Numerical Combustion, Granada, Spain, April 23-26, 2006

\section{Special Recognitions \& Awards/Patents Issued}

1. SAE Oral Presentation Award for SAE (presentation 3 above).

\section{Acronyms}

BDC: Bottom dead center position of the piston during the engine cycle. CFD: Computational fluid dynamics 
DIB: Di-isobutylene. When used in an engine, it normally consists of two isomers with carbon skeletal structures shown in Fig. 6

HCCI: Homogeneous-charge, compression-ignition engine

LLNL: Lawrence Livermore National Laboratory

MCH: Methyl cyclohexane. Its carbon skeletal structure is shown in Fig. 6

NOx: Oxides of nitrogen, $\mathrm{NO}_{2}, \mathrm{NO}$

TDC: Top dead center position of the piston during the engine cycle.

\section{Figure Captions:}

Figure 1. The temperature required at bottom dead center to maintain ignition phasing at top dead center in an HCCI engine at Sandia. (Ignition phasing is determined by the 50 percent burn point.) The equivalence ratio is varied by changing the amount of fuel injected into the engine. The fuel is diisobutylene. The points are the experiments and the curve is the result of the model. Engine speed is $1200 \mathrm{rpm}$ and the intake pressure is $100 \mathrm{kPa}$.

Figure 2. Experimental (points) and model-predicted ignition-delay times (curves) at 10, 15 and $20 \mathrm{~atm}$ for methylcyclohexane in a rapid compression machine. The experiments were performed at the National University of Ireland in Galway.

Figure 3. The temperature required at bottom dead center to maintain ignition phasing at top dead center in an HCCI engine at Sandia. (Ignition phasing is determined by the 50 percent burn point.) The equivalence ratio is varied by changing the amount of fuel injected into the engine. The fuel is MCH. The points are the experimental results. The curves show the simulated results for a previous MCH model (dotted curve) and an improved MCH model (solid curve).

Figure 4. Experimental (points) and model predicted ignition delay times (red solid curve) at 7-9 atm for cyclohexane in a rapid compression machine. The experiments were performed at University of Sciences and Technology, Lille, France. Open symbols and the dashed curve correspond to cool flame ignition measurements and predictions, respectively.

Figure 5. Major intermediate products produced in the oxidation of cyclohexane in the rapid compression machine. Cyclohexene (navy blue, experimental (points), model (curve)) and hex-5enal (red, experimental (points), model (curve)). The percentage of carbon in the fuel that is contained in the intermediate product is plotted as a function of fuel consumed. The experiments were performed at University of Sciences and Technology, Lille, France.

Figure 6. Carbon skeletal structures of fuels for which detailed chemical kinetic mechanisms have been developed: diisobutylene, methylcyclohexane and cyclohexane. 


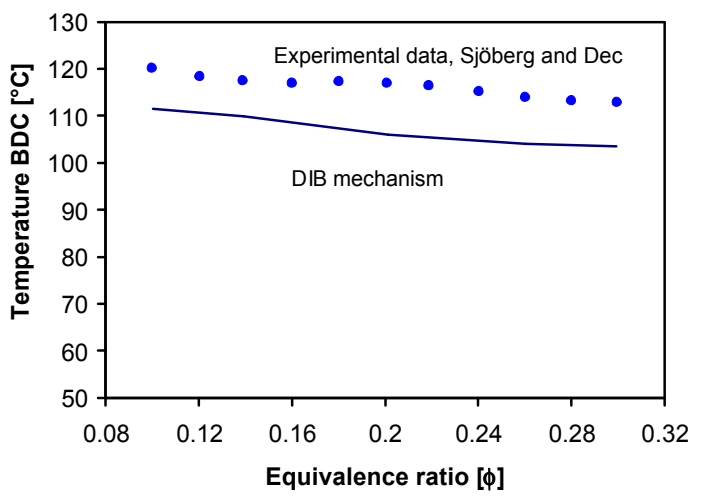

Figure 1. The temperature required at bottom dead center to maintain ignition phasing at top dead center in an HCCI engine at Sandia. (Ignition phasing is determined by the 50 percent burn point.) The equivalence ratio is varied by changing the amount of fuel injected into the engine. The fuel is diisobutylene. The points are the experiments and the curve is the result of the model. Engine speed is $1200 \mathrm{rpm}$. Intake pressure is $100 \mathrm{kPa}$.

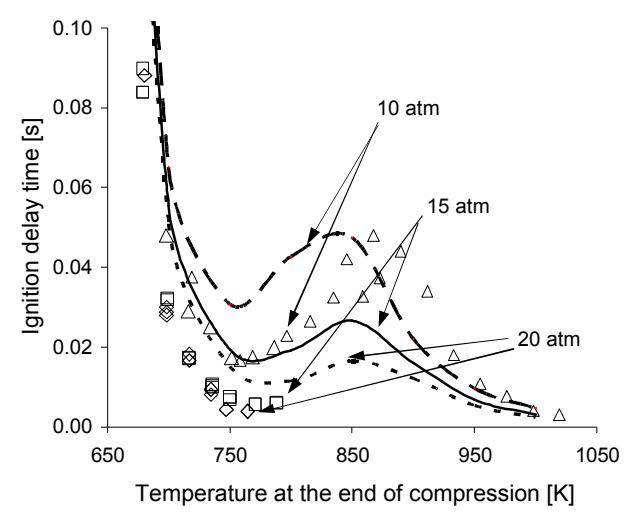

Figure 2. Experimental (points) and model predicted ignition delay times (line) at 10, 15 and 20 atm for methylcyclohexane in a rapid compression machine. The experiments were performed at the National University of Ireland in Galway. 


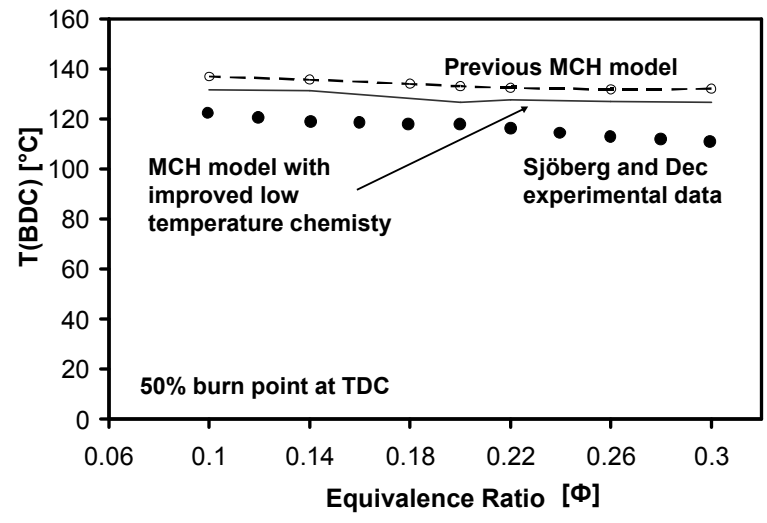

Figure 3. The temperature required at bottom dead center to maintain ignition phasing at top dead center in an HCCI engine at Sandia. (Ignition phasing is determined by the 50 percent burn point.) The equivalence ratio is varied by changing the amount of fuel injected into the engine. The fuel is $\mathrm{MCH}$. The points are the experiments. The curves show the results with a gasoline surrogate mechanism containing a previous $\mathrm{MCH}$ model (dotted lines) and an improved $\mathrm{MCH}$ model.

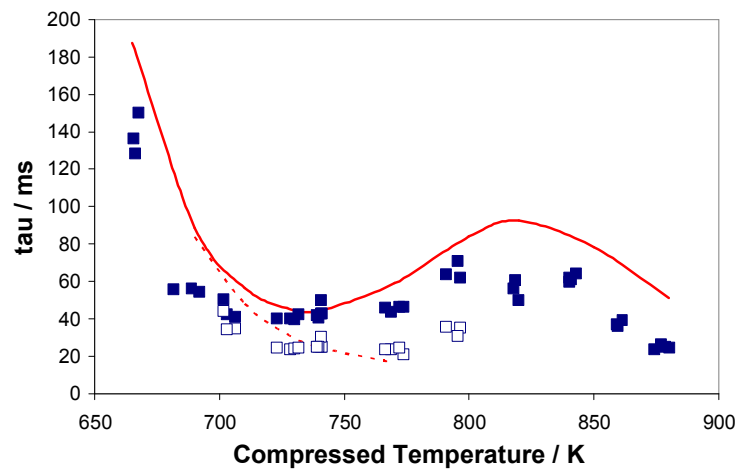

Figure 4. Experimental (points), pressure range 7-9 atm and model predicted ignition delay times (line) at $8 \mathrm{~atm}$ for cyclohexane in a rapid compression machine. The experiments were performed at University of Sciences and Technology, Lille, France. Open symbols and dashed lines correspond to cool flame ignition measurements. 


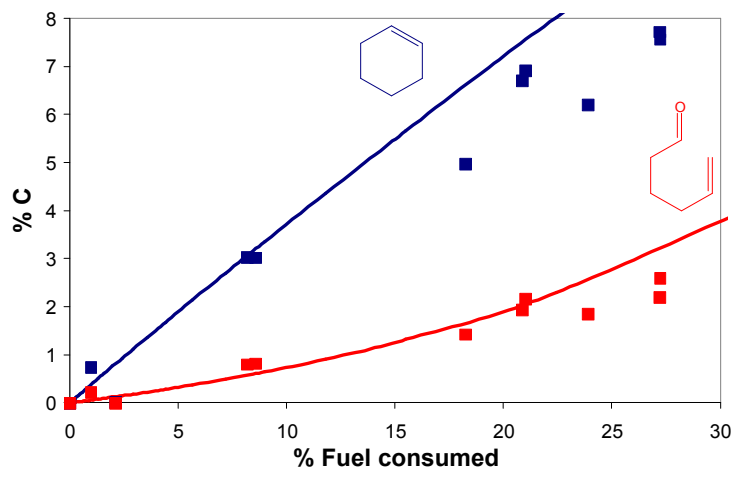

Figure 5. Major intermediate products produced in the oxidation of cyclohexane in the rapid compression machine. Cyclohexene (navy blue, experimental (points), model (lines)) and hex-5-enal (red, experimental (points), model (lines)). The percentage of carbon in the fuel that is contained in the intermediate product as a function of fuel consumed is plotted. The experiments were performed at University of Sciences and Technology, Lille, France.
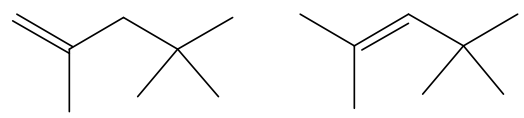

isomers of diisobutylene<smiles>CC1CCCCC1</smiles><smiles>C1CCCCC1</smiles>

methyl cyclohexane

cyclohexane

Figure 6. Carbon skeletal structures of fuels for which detailed chemical kinetic mechanisms have been developed: diisobutylene, methylcyclohexane and cyclohexane. 